
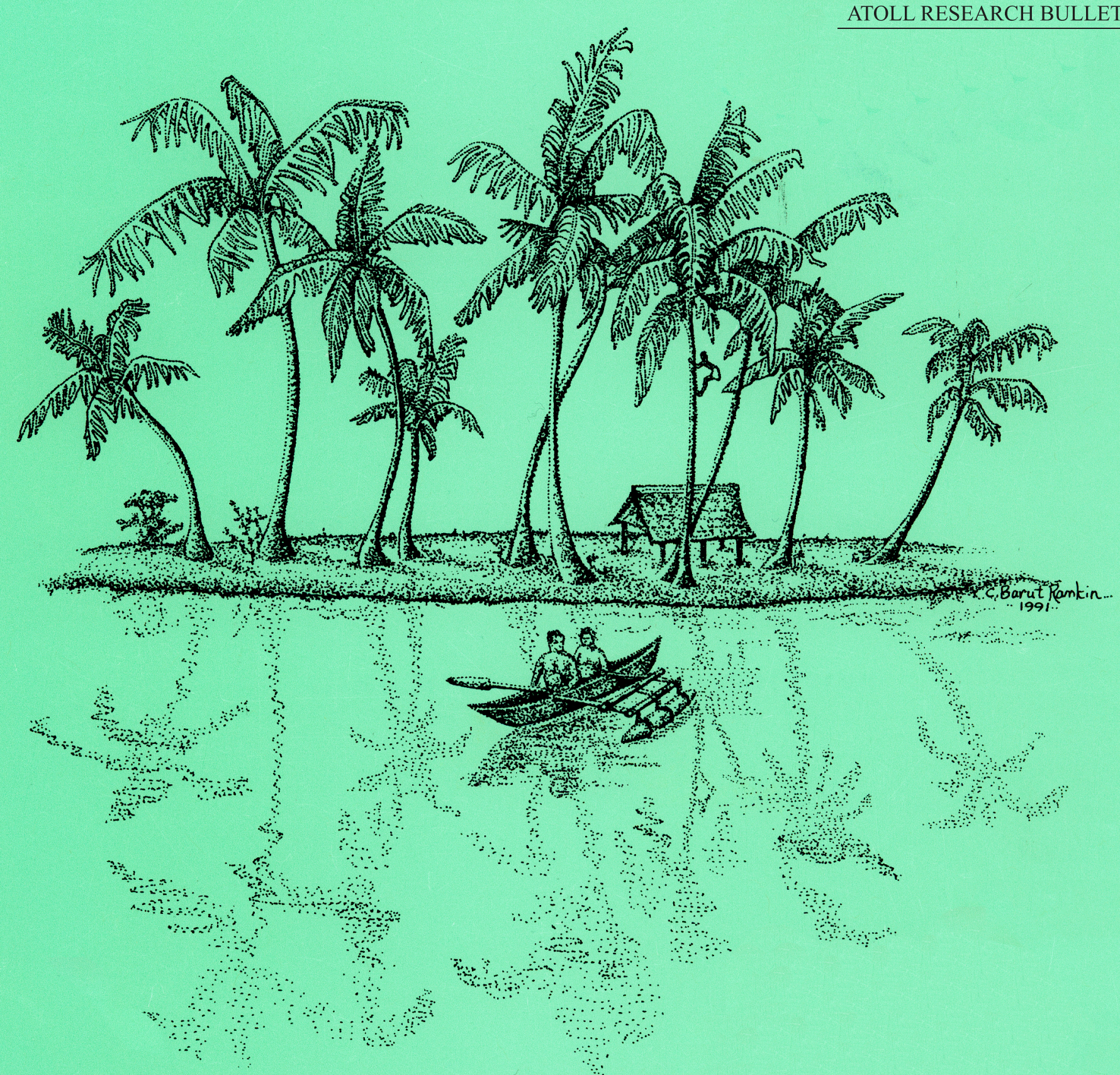

ARE LAKSHADWEEP CORALS HEADING TOWARD COT OUTBREAK?

L. Senthilnathan, R. Ranith, M. Machendiranathan, T. Thangaradjou, Idrees Babu, S.B. Choudhury, I.V. Ramana, and S.K. Sasamal

Smithsonian Institution Scholarly Press

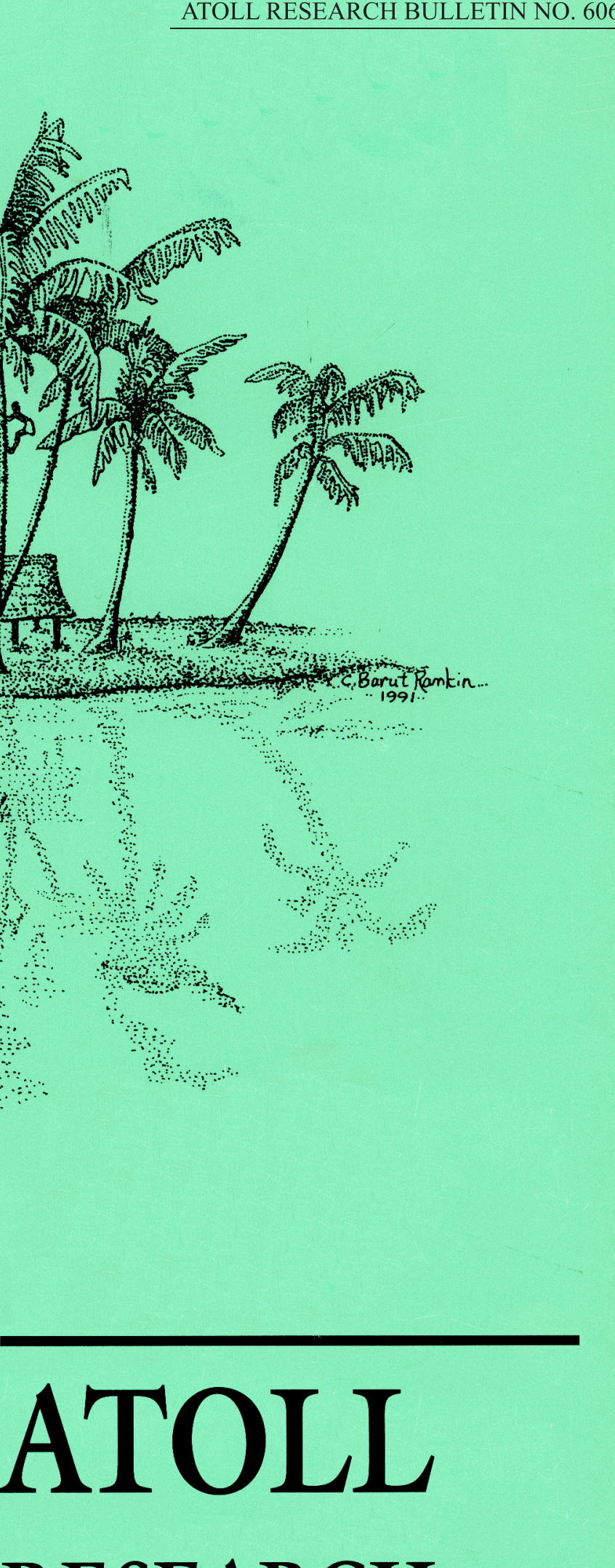

\section{ATOLL}

RESEARCH

BULLETIN 


\section{ARE LAKSHADWEEP CORALS HEADING TOWARD COT OUTBREAK?}

L. Senthilnathan, R. Ranith, M. Machendiranathan, T. Thangaradjou, Idrees Babu, S.B. Choudhury, I.V. Ramana, and S.K. Sasamal

Atoll Research Bulletin No. 606 • 23 October 2014 
All statements made in papers published in the Atoll Research Bulletin are the sole responsibility of the authors and do not necessarily represent the views of the Smithsonian Institution or of the editors of the Bulletin. Articles submitted for publication in the Atoll Research Bulletin should be original papers and must be made available by authors for open access publication. Manuscripts should be consistent with the "Author Formatting Guidelines for Publication in the Atoll Research Bulletin." All submissions to the Bulletin are peer reviewed and, after revision, are evaluated prior to acceptance and publication through the publisher's open access portal, Open SI (http://opensi.si.edu).

Published by SMITHSONIAN INSTITUTION SCHOLARLY PRESS

P.O. Box 37012, MRC 957

Washington, D.C. 20013-7012

www.scholarlypress.si.edu

The rights to all text and images in this publication are owned either by the contributing authors or third parties. Fair use of materials is permitted for personal, educational, or noncommercial purposes. Users must cite author and source of content, must not alter or modify the content, and must comply with all other terms or restrictions that may be applicable. Users are responsible for securing permission from a rights holder for any other use.

ISSN: 0077-5630 (online) 


\title{
ARE LAKSHADWEEP CORALS HEADING TOWARD COT OUTBREAK?
}

\author{
L. SENTHILNATHAN ${ }^{1}$, R. RANITH ${ }^{1}$, M. MACHENDIRANATHAN ${ }^{1}$, T. THANGARADJOU ${ }^{1 *}$, \\ IDREES BABU ${ }^{2}$, S.B. CHOUDHURY ${ }^{3}$, I.V. RAMANA ${ }^{3}$, and S.K. SASAMAL ${ }^{3}$
}

\begin{abstract}
Crown-of-Thorns (COT) predation off Kavaratti and Agatti islands in the Lakshadweep reef system has increased sporadically in recent years and appears to be approaching outbreak status, as indicated by a study of the starfish's spatial progression along 16 transects off each island between 2010 and 2012. Infestation along one transect rose from 3 COTs in 2010 to 18 COTs in 2012. A threat susceptibility level for corals calculated as stressors/total live corals present along each transect averaged $38.9 \%$ to $52.5 \%$ in 2011 and 43.5 to $52.6 \%$ in 2012. Over much of the study period, COT exhibited selective feeding on branching corals but then shifted to Pavona sp. during 2012. High periodicity in COT prevalence was also observed, with a higher population during March-May (pre monsoon) and August-September (post monsoon), months when the corals were under severe environmental stress.
\end{abstract}

Keywords: Predation, COT, threat susceptibility, massive corals, infestation, prevalence

\section{INTRODUCTION}

Coral reefs are highly diverse tropical ecosystems under threat of collapse as a result of numerous natural and anthropogenic stresses (Hughes et al., 2003; Hoegh-Guldberg et al., 2009; Baker et al., 2008; Borke et al, 2011; McClanahan et al., 2012). Elevated SST, ocean acidification, anthropogenic activities, diseases, and sedimentation are among the presumed major threats to coral endurance (Ateweberhan et al., 2013). However, the list also includes predation by a variety of organisms, now deemed a prime issue for coral reef health, but which has received insufficient attention until recently (Bruckner et al., 2000; Glynn, 2004; Rotjan et al., 2006). Despite reports on coral predation and corallivore dynamics worldwide, predation was not considered a major threat to coral reefs until the late 1950s, when islands of the Great Barrier Reef experienced a major Crown-of-Thorns (COT) (Acanthaster planci) outbreak in 1959 that decimated an average 50\% of coral cover in many reefs there (Endean, 1969; Chesher, 1969; Birkeland, 1982). Since then research on the impact of COT on corals has gained momentum, notably through additional alarming reports of COT destruction in other Indo-Pacific reefs (Moran, 1990; Endean et al., 1988; Van Woesik, 1994; Sweatman et al., 2011). Although COT tends to occur in low numbers in most reefs, outbreaks of this voracious coral predator can completely destroy a reef's coral cover (Rotjan and Lewis, 2008; Stella et al., 2011). Individual COTs are capable of consuming about one square meter of coral per month (Pratchett, 2001; Porter, 1972). Interestingly, species-specific predation of COT on fastgrowing species such as Acropora sp., Montipora sp., and Pocillopra sp. may be so intense that COT predators such as Triton sp. have limited impact on slowing the destruction (Pratchett, 2001).

COT's rate of coral consumption varies quantitatively with environmental conditions as well as its population density in each region (Moron and De'ath, 1992). At low densities, COT seems to feed at

\footnotetext{
${ }^{1}$ Centre of Advanced Studies in Marine Biology, Faculty of Marine Sciences, Annamalai University, Parangipettai - 608 502, Tamilnadu, India.

${ }^{2}$ Department of Science and Technology, Kavaratti, Union Territory of Lakshadweep, India.

${ }^{3}$ National Remote Sensing Centre, Indian Space Research Organisation, (Department of Space, Government of India), Balanagar, Hyderabad - 500 625, Andhra Pradesh, India.

*Corresponding author. E-mail: umaradjou@gmail.com; Telefax: +91 4144-252099.
} 
random, avoiding exposed reef areas and remaining in areas of low wave action. During outbreaks, it tends to feed continuously even in the outer lagoon, leaving large areas of dead coral and thus causing a major shift in the diversity of the reef community (Pratchett, 2001).

COT was first reported in the Lakshadweep reef system by Pillai (1986), who noted the population posed no severe threat to the reef system there. Subsequently COT population dynamics and resulting coral mortality in the Lakshadweep Islands received little attention, except for occasional mention of its sparse occurrence (Arthur, 2000).

The present study provides a preliminary assessment of the population density, persistence, and predation periodicity of COT in Kavaratti and Agatti islands of Lakshadweep. It also identifies the factors favoring COT population explosions and persistence as a major threat to the coral reefs of Lakshadweep in the future.

\section{MATERIALS AND METHODS}

\section{Study Area}

Lakshadweep islands are a group of twelve atoll formations in the Arabian Sea about 200- $400 \mathrm{~km}$ from and parallel to the Kerala, India, coast (Figure 1). The present survey was conducted at Kavaratti and Agatti islands of this group (Figure 1). Corals are diverse and abundant throughout the region with generally low exposure to competition and thus show an immediate response to small-scale disturbances (Pillai, 1986; Arthur, 2006; Venkatraman, 2012). Inner lagoon reefs are hydrodynamically more isolated and are seldom exposed to competition (Black \& Moran, 1991). Hence a major ecosystem disturbance like COT predation has an even greater impact (Bode et al., 1992). The present survey was conducted at Lakshadweep lagoon to elucidate the extent of this impact. The results of this work can be used as baseline data for better ecosystem management.

These particular islands were selected for study because their unique environmental conditions have bearing on coral predation dynamics. For convenience, Kavaratti and Agatti lagoons were divided into northern and southern regimes based on the coral type, coral cover, health status, and topographic differences. Lagoons of these islands are highly impacted by human activity, unrestricted fishing, and transportation and tourism activities, all of which have led to the partial destruction of their coral cover. As pointed out in earlier studies, these corals have also experienced major physiological stresses and thus are highly vulnerable to any further natural and human-related pressures (Pillai, 1986; Arthur, 2000; Arthur, 2006; Venkatraman, 2012).

\section{Coral Reef Cover and Health Status}

The health and extent of coral cover were examined along 16 transects established perpendicular to shore in the manner of Loya (1978) in Kavaratti and Agatti lagoons before and after monsoon seasons in 2010, 2011, and 2012. These transects were laid out at depths of 2 to 5 meters in the northern and southern regimes off each island. Observations were repeated in regions with suspicious health conditions such as paling, bleaching, and other visible symptoms to ascertain the prevailing situation; this is discussed in a separate report. Benthic features (coral species, percentage cover, and health status) were observed along Line Intercept Transects (LIT). Corals that contribute to more than $50 \%$ of the total reef cover per transect were considered a major reef component. Prevailing types were classified into branching, massive, and other reef forms. Information on the coral cover, COT population, and threat susceptibility over the study area during 2010 was obtained from coral surveys of Lakshadweep's Department of Science and Technology (DST). The percentage of stress present and the total live corals in each transect were used to compute the threat susceptibility in the region. 



Figure 1. Location of the study area and transects within the lagoon of the respective islands.

\section{COT Population Estimation}

In keeping with "belt" transects recommended for accurate assessment of benthic communities (Mapstone \& Ayling, 1994), $50 \times$ 5-meter belt transects were established at both islands by snorkeling 
and skin diving at depths of 2 to $5 \mathrm{~m}$. Regions with high coral cover and high threat susceptibility levels established during the study were assessed to determine the extent and behavior of the COT population and its impact. Replicate transects were laid out in the regions suspected to be under COT attack to affirm a persistent population and rate of feeding progression. All COT animals intercepted within the belts were counted. Predation and predatory marks were captured in underwater photos using a Canon Powershot Dseries camera. Threat susceptibility was calculated as a ratio between stress (as indicated by paling and bleaching; diseases; overexposure to air, and other physical disturbances) and live coral cover, and was used as a predictor for COT incidence and feeding. In order to statistically derive the variability in COT population during the years 2010-2012 and to identify the relationship of observed parameters in maintaining the COT population dynamics, paired t-test and correlation analysis was carried out using SPSS 16.0.

\section{RESULTS}

When plotted on a graph (Figure 2), the frequency and variation in distribution of COT populations indicate a gradual population increase over the three-year study period. A minimum of 3 and maximum of 18 COTs per transect were recorded during 2010 and 2012, respectively. The average number of COT increased from 2 per transect during 2010 to 6 per transect in 2012. Starfish sightings were inconsistent during the three years. In 2010, 100\% of COT incidence was recorded off Agatti Island, with zero sightings off Kavaratti Island. By contrast, in 2011, 33\% of the COT sightings occurred off Kavaratti and 67\% off Agatti Island. In 2012 COT sightings at Kavaratti rose to 40\%, while at Agatti they dropped to $60 \%$. Though it appears that there is a COT migration pattern from north to south, solid conclusions on migration can only be achieved if the study is extended to all the islands of Lakshadweep. In the present study current patterns have not been considered, but a seasonal north-south current pattern is reported for the region.

At the same time, the distribution of major coral types off Kavaratti and Agatti changed noticeably during the study period (Figure 3). Predominant massive corals off Kavaratti declined from $68.75 \%$ in 2010 to 50\% in 2011 and 37.5\% in 2012. Transects KS7 and KN8 off Kavaratti consisted predominantly of massive reef forms in 2010, but dominant forms shifted to Pavona and other reef types during 2011 and 2012. The percentage of branching forms off Kavaratti averaged 31\%. Meanwhile, off Agatti Island branching forms were dominant, with an average cover of 75\% during 2010 and 2011, which dropped to 62.5\% in 2012. During 2011 and 2012, the average threat (disease, sedimentation, macro algal cover growth) susceptibility off Kavaratti and Agatti increased from $38.9 \%$ to $52.5 \%$ and 43.5 to $52.6 \%$, respectively.
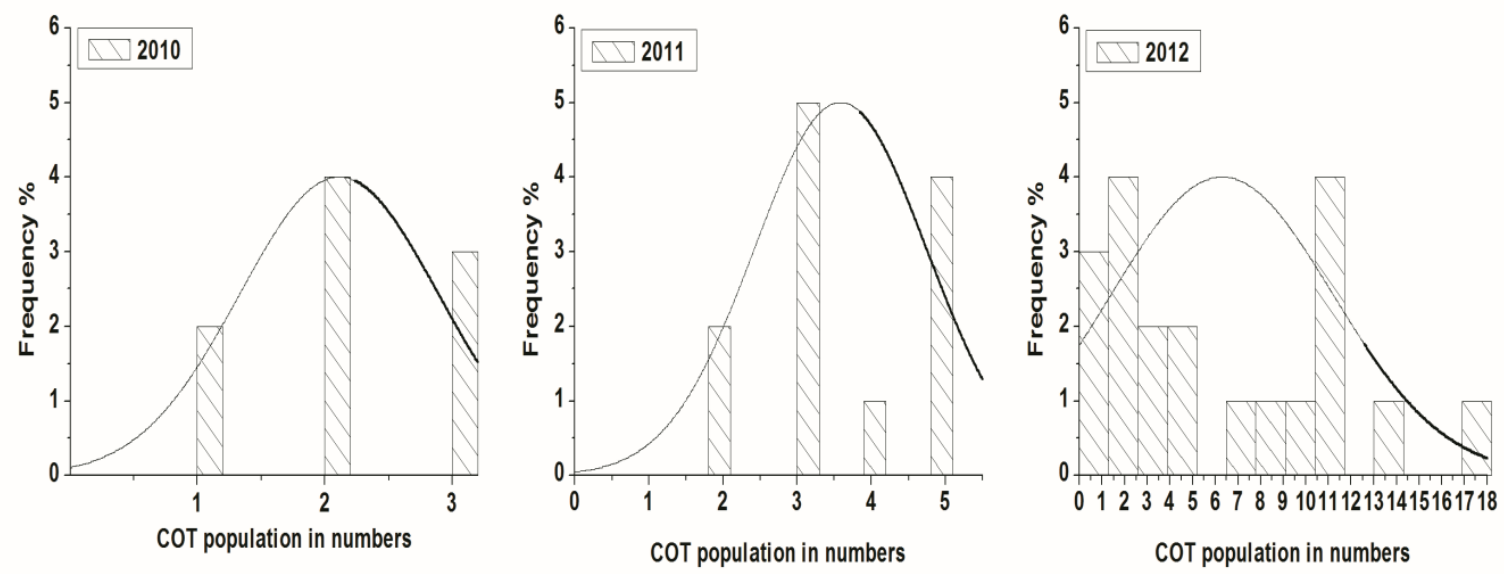

Figure 2. Frequency distribution of COT. 

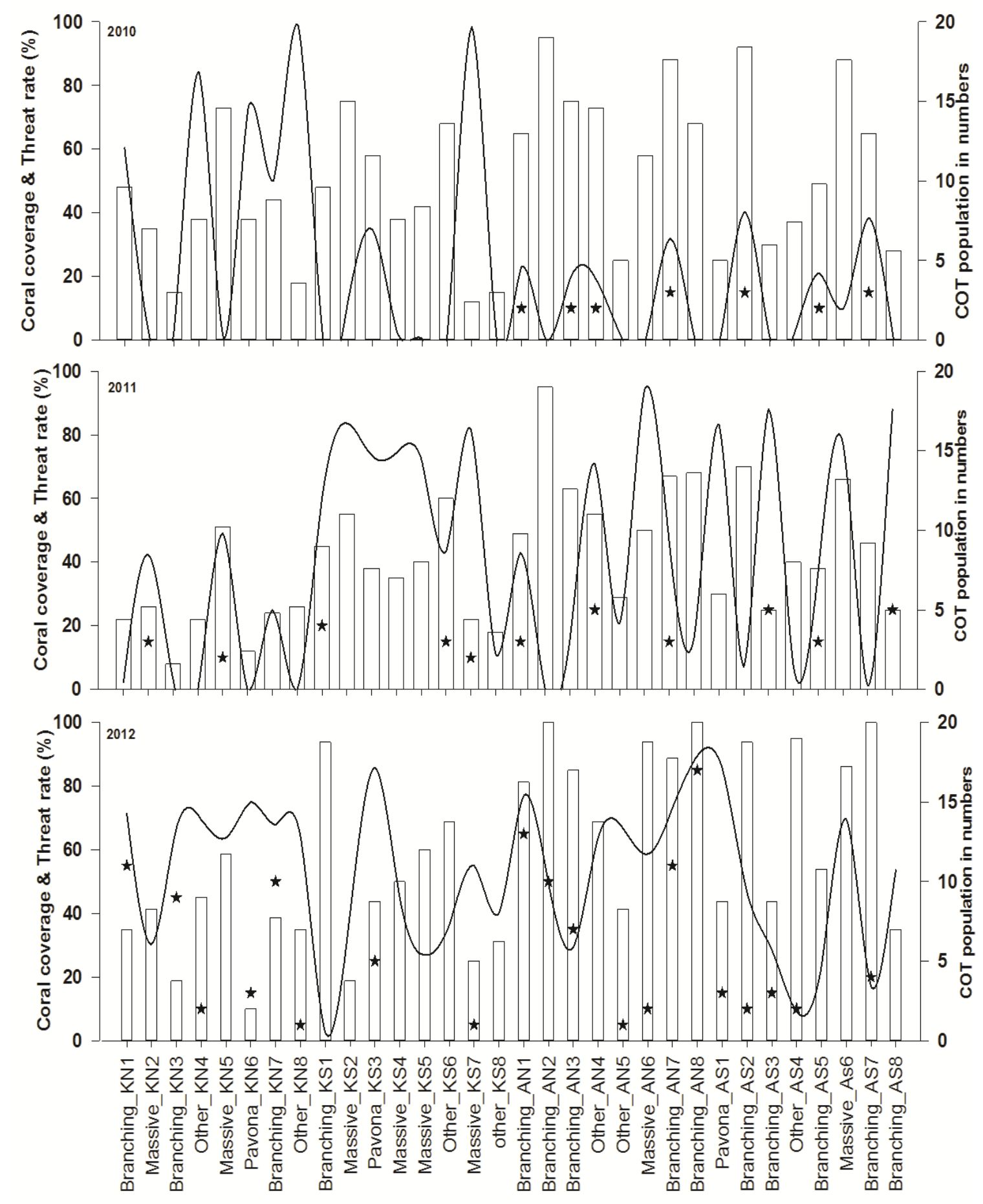

\section{Major coral form in transects}

coral cover

* Major coral form vs COT Population

Major coral form vs Threat susceptibility

Figure 3. Major benthic changes during the study period. 
COT occurrence increased in the 2011 transects with an increase in threat susceptibility (Figure 3). Field observations showed that COT preferred to graze on branching forms at that time, especially Acroporidae (Figure 4). In 2012, however, COT was also found at sites abundant with Pavona, where it preferred to stay in the shade of massive coral forms in the daytime for defense against COT predators (Figure 5), but excluded massive forms from its diet.

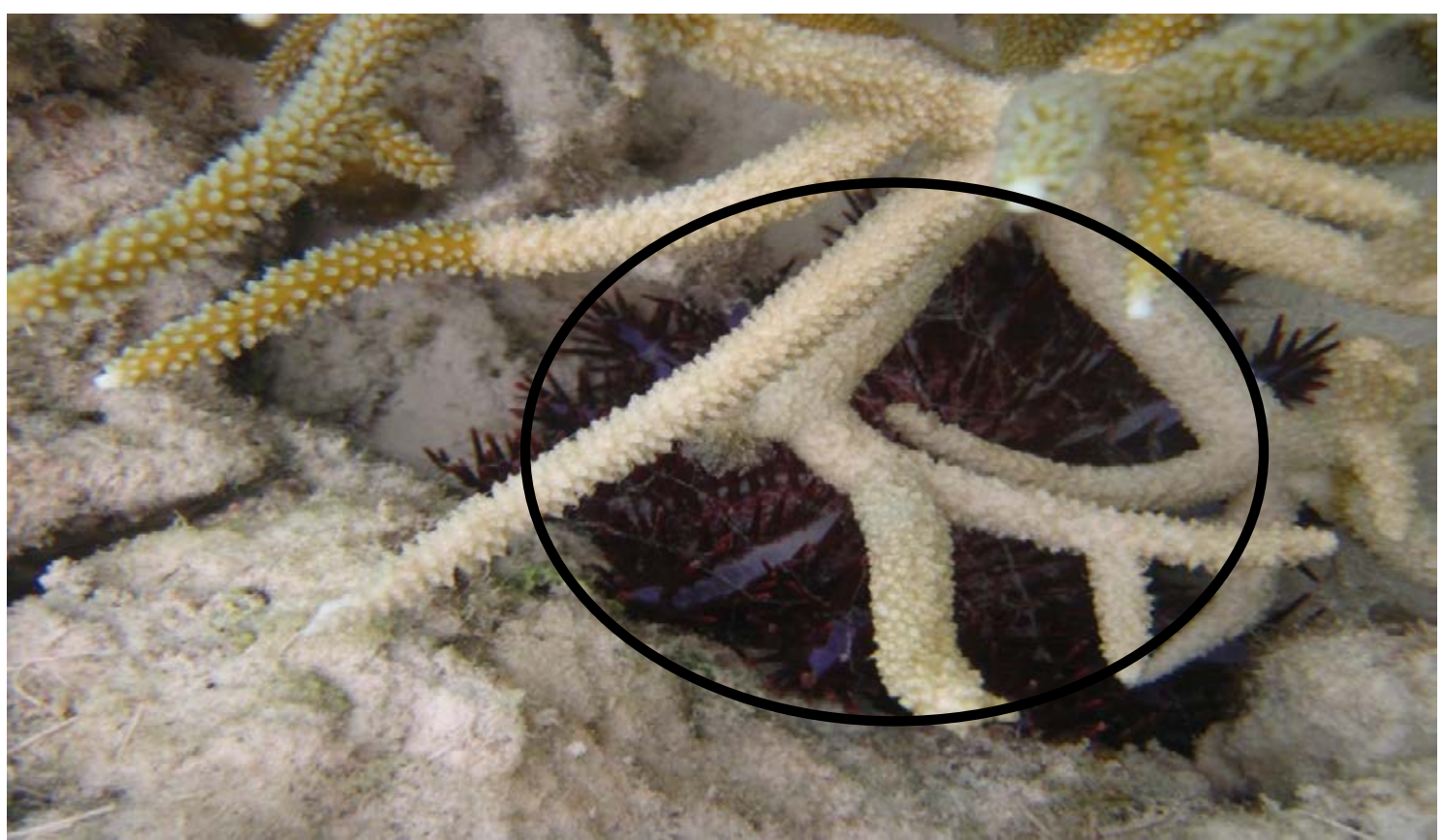

Figure 4. Feeding scar of COT infestation on Acropora sp.

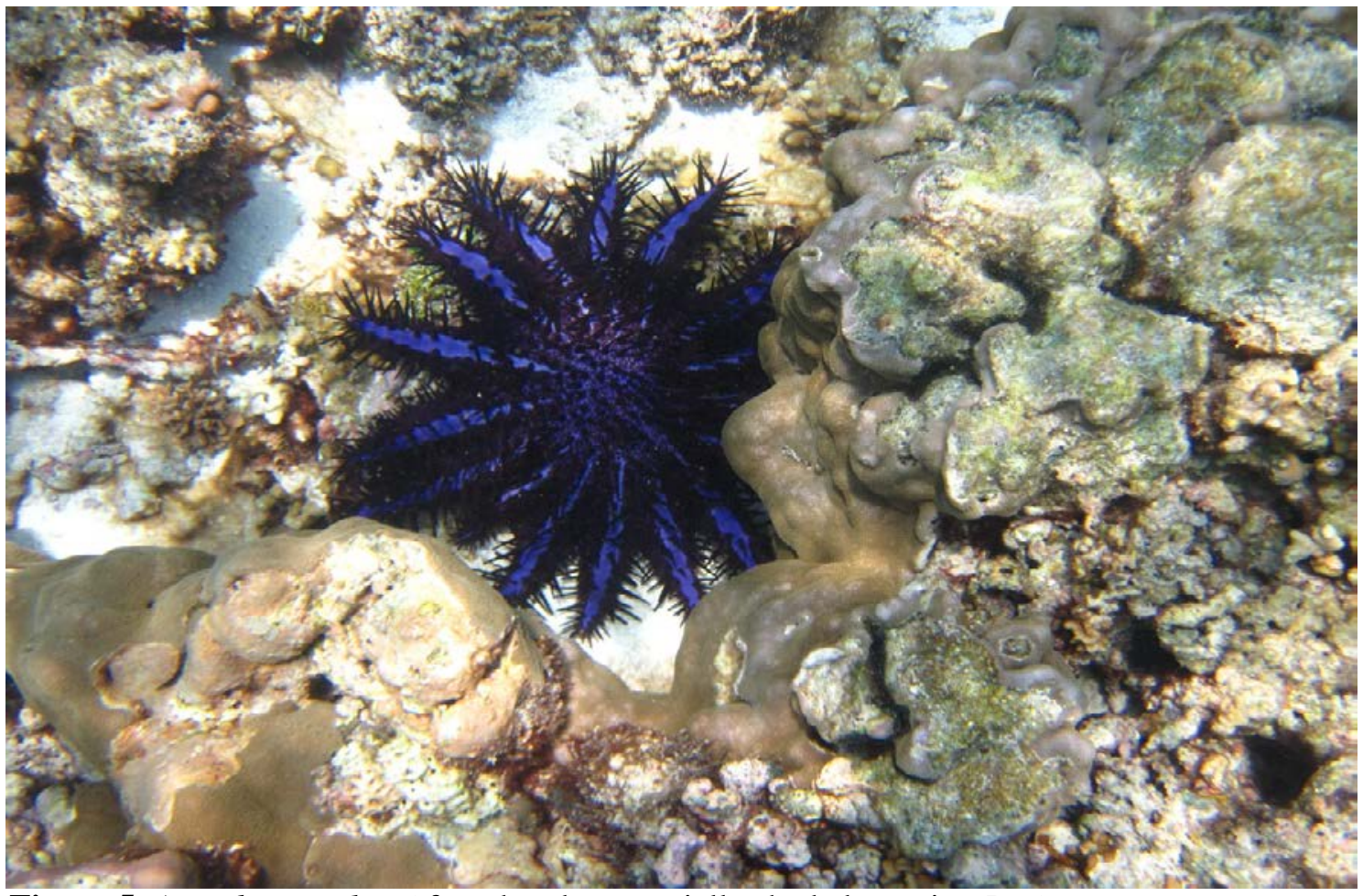

Figure 5. Acanthaster planci found under a partially shaded massive Porites sp. 
Clear seasonal variation in the COT population was recorded during March-May (pre-monsoon) and August-September (post-monsoon) in all surveys from 2010 to 2012 (Figure 6). The predominance of COT populations was found to be high during the pre-monsoon period with an average of 11 animals per belt, and a minimum of 3 animals per belt during the post-monsoon season.



Figure 6. Seasonality in Crown-of-Thorn events.

A paired sample $t$-test comparing the variation in COT populations since 2010 showed no significant difference between 2010 and $2011(\mathrm{M}=-0.58 ; \mathrm{SD}=2.05 ; \mathrm{t}=-1.61 ; \mathrm{p}=0.116)$ but indicated significant differences between 2011 and $2012(\mathrm{M}=-2.4 ; \mathrm{SD}=5.28$; $\mathrm{t}=-5.2 ; \mathrm{p}=0.014)$, and between 2010 and 2012 $(\mathrm{M}=-2.97 ; \mathrm{SD}=4.74 ; \mathrm{t}=-3.6$ and $\mathrm{p}=0.001)$.

Correlation analysis indicated that the threat susceptibility of corals has a positive relationship (Pearson $r=0.410$ ) with an increase in the COT population when compared with coral cover (Pearson $r=$ 0.270). At the same time, coral cover demonstrated a negative relationship with the coral threat susceptibility (Pearson $r=-0.038$ ). Significant two-tailed values obtained from the correlation analysis showed a statistically significant correlation between COT population and threat susceptibility (0.001).

\section{DISCUSSION}

COT off Kavaratti and Agatti appeared to prefer to feed on coral colonies showing significant tissue damage and exposed to physical disturbances. When stresses such as monsoon-induced turbidity, resuspension of sediments (Chandramohan et al., 1993), and predation coincide with elevated SSTs, the stress level in coral reefs rises from low to high. Impaired coral defensive mechanisms (sweeper tentacles, mucus production) experienced by the reefs as a result of the increased physical stressors could have 
attracted more COT populations in Lakshadweep waters during the pre- and post-monsoon seasons. Such a reduction in coral defensive mechanisms during periods of high physical stress has been observed by Pratchett (2001). Though nutrient enrichment due to terrestrial runoff and consequent turbidity enhances primary productivity and tends to attract COT larvae (Birkeland, 1982), the present study area are small islands more than $400 \mathrm{~km}$ away from the mainland coast; hence the possibility of terrestrial runoff is nullified in this case.

The increased threat susceptibility and vulnerability of corals to predation during the pre- and postmonsoon seasons coincides with the periodic occurrence of COT starfish in the study area. The ecosystem experienced more stressful conditions during the pre-monsoon period, as reflected in the seasonal variation in COT occurrence. The increase in COT frequency and distribution in the Lakshadweep islands may be related to multiple factors, as revealed during the three years of the survey. Warm SST during the pre-monsoon period; progressively warmer winters and decreased monsoon rainfall (Kumar \& Prasad, 1996); and low wind action during August-September (Kumar et al., 2009) increase SST and stress factors among corals of the Lakshadweep islands. Spiked SSTs observed during the pre-monsoon period causes sporadic stress to the live reef forms and is thought to be a major factor causing coral bleaching (Arthur, 2000). Apart from the bleaching events, rising ocean temperatures would exacerbate the impact and persistence of coral diseases in reef ecosystems (Selig et al., 2006). Seasonal recurrence of COT during the stressful pre-monsoon periods corroborated the earlier observations of Selig et al. (2006) that heavily disturbed reefs tend to be more seriously affected by COT than are undisturbed reefs.

Benthic cover on the surveyed transects in the Kavaratti and Agatti islands during 2010 consisted mainly of massive and branching corals, respectively. The percentage of branching corals off Agatti (aggregated from north and south transects) was found to be relatively higher than off Kavaratti. The abundance of branching corals off Agatti provided extensive space for COT to settle and demonstrate its preference for branching corals, most notably Acropora sp. (Moran, 1996; Pratchett, 2001). Kavaratti's massive forms were ignored by COT, which left these corals undisturbed during 2010. However, COT's feeding behavior shifted from branched forms to selective Pavona sp. in 2012, allowing COT to extend its area of occurrence. The threat susceptibility for Kavaratti corals was higher than for Agatti corals as a result of exposure to multiple stressors, such as sediment resuspension, diseases, predators, and long aerial exposure. The dominance of massive reef forms off Kavaratti also accounted for its higher threat susceptibility when compared with Agatti, which is dominated by branching forms. As numerous studies have demonstrated, massive corals are more susceptible to a variety of stresses, which may explain why the cumulative threat susceptibility was higher off this island. The low number of branching corals and high density of massive forms not preferred by COT might explain the sparse COT population in Kavaratti during 2010 even though the threat susceptibility was high.

Increased threat susceptibility and recurrent bleaching events in 2010 played a major role in the dramatic community shift among coral species in Kavaratti and Agatti islands. Sites characterized by a high threat susceptibility have experienced small or large scale community transformation: transects KS7 and KN8, in particular, saw a sporadic yet prominent community shift from the importunate threat recorded during 2010. Massive forms that were extensive in transects KS7 and KN8 were replaced by overgrowing Pavona sp. and other reef types by 2011. The opportunistic growth and competition among coral species induced by elevated stress, which reduced the defense capability of corals in the area, can be considered a key reason for such an erratic community shift in a small time interval (Baird \& Hughes, 2000). Community shift was ongoing in 2012, when 9 of 16 transects surveyed off Kavaratti and 3 of 16 transects surveyed off Agatti experienced such shifts. An increased cover of live branching coral due to a community shift might attract the Acanthaster sp. population to extend its territory down to Kavaratti. An increased cover of COT's preferred coral type and higher threat susceptibility enabled the starfish to spread to places it had not appeared in before. In 2012 COT also expanded its feeding behavior to include selective massive coral forms (Porites sp. and Pavona sp.) (Figure 7). Limited availability of COT's preferred food and the need to satisfy its nutrient requirement may be why the starfish began to feed on non-preferred massive forms (Pratchett, 2001). 


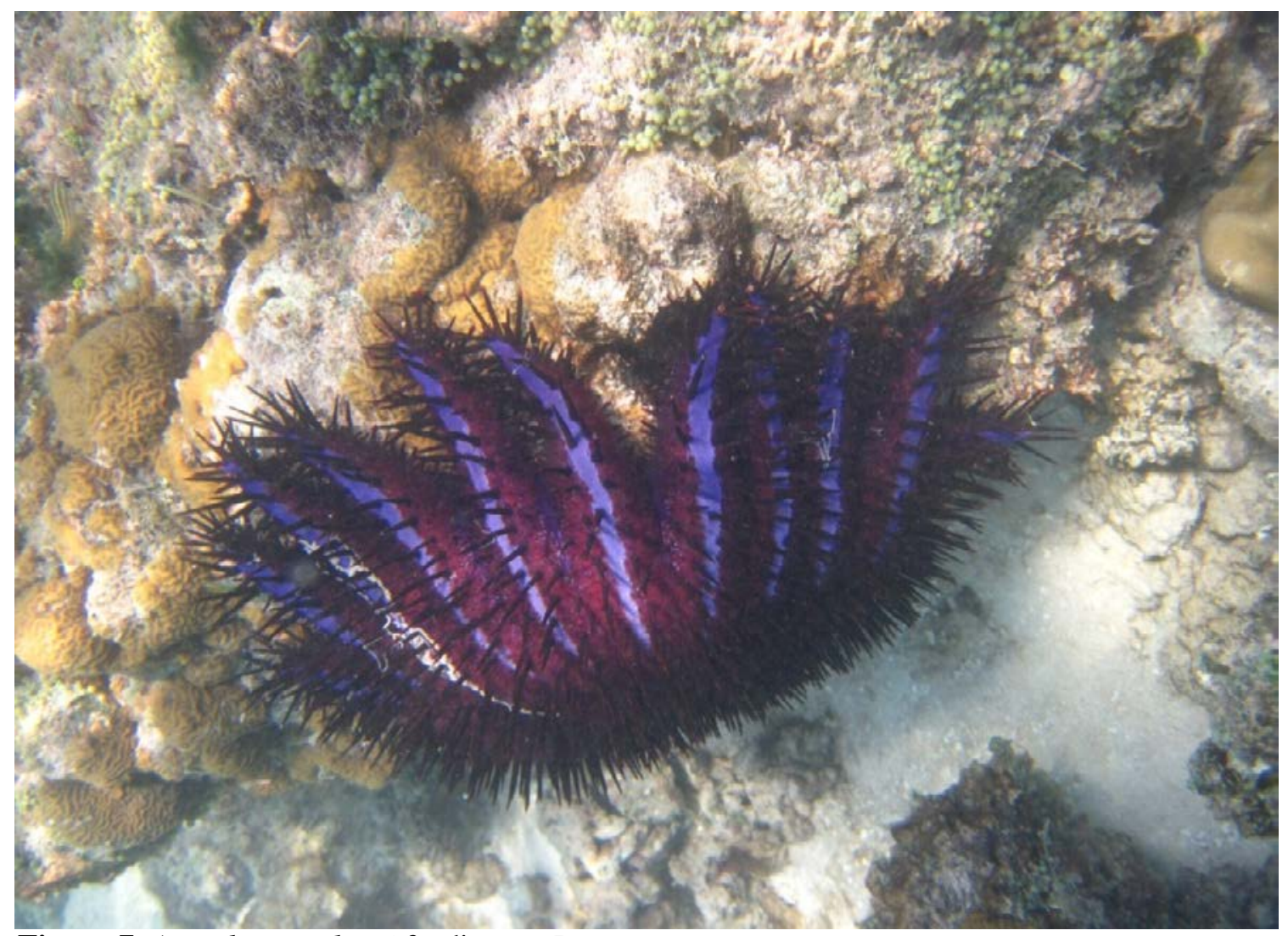

Figure 7. Acanthaster planci feeding on Pavona sp.

Statistically significant variability in the COT population since 2010, as revealed in $t$-test results, shed light on the relationship of various parameters to COT density. The results suggest that the occurrence of COT populations depends upon the degree of threat in a region and not solely on the presence of live coral cover. The Kavaratti and Agatti transects with a high threat susceptibility coincided with higher COT populations, while those with a lower threat susceptibility had lower COT density. Thus an increased threat susceptibility at a site can override the specific type of coral cover for COT predation, resulting in community destruction of the ecosystem.

Results of the present study point to a sporadic yet steady increase in the rate of threat to corals and increased damage to the reef community in the Lakshadweep region. COT not only feeds on corals but also has an impact on ecosystem stability, as confirmed by the results of the shift in its feeding behavior in the study area. Comprehensively designed monitoring and management, including periodic surveys over the reef system for any COT occurrence, should be given immediate attention as the present stress levels and community shifts point to the possibility of a near-future COT outbreak in the Lakshadweep reef system.

\section{ACKNOWLEDGMENTS}

The authors are grateful to Prof. K. Kathiresan, Director and Dean, and Prof. T. Balasubramanian, former Director and Dean, Centre for Advanced Studies (CAS) in Marine Biology, Annamalai University, for support and encouragement. The authors also thank the National Remote Sensing Centre, Hyderabad, for providing the financial support, and the Department of Science and Technology and Department of Environment and Forest, Lakshadweep, for providing necessary permission and support to conduct the coral reef survey. Venka Macintyre provided an English-language revision of this paper. 


\section{REFERENCES}

Arthur, R. 2000. Coral bleaching and mortality in three Indian reef regions during an El-Nino southern oscillation event. Current Science, 79:1723-1729.

Arthur, R., T. J. Done, H. Marsh, and V. Harriott. 2006. Local processes strongly influence postbleaching benthic recovery in the Lakshadweep Islands. Coral Reefs, 25: 427-440.

Ateweberhan, M., D. A. Feary, S. Keshavmurthy, A. Chen, M. H. Schleyer, and C. R. C. Sheppard. 2013. Climate change impacts on coral reefs: Synergies with local effects, possibilities for acclimation, and management implications. Marine Pollution Bulletin, 74(2):526-539.

Baird, A. H., and T. P. Hughes. 2000. Competitive dominance by tabular corals: an experimental analysis of recruitment and survival of understorey assemblages. Journal of Experimental Marine Biology and Ecology, 251:117-132.

Baker, A. C., P. W. Glynn, B. Riegl. 2008. Climate change and coral reef bleaching: an ecological assessment of the long-term impacts, recovery trends and future outlooks. Estuarine, Coastal and Shelf Science, 80:435-471.

Birkeland, C. 1982. Terrestrial runoff as a cause of outbreaks of Acanthaster planci (Echinodermata: Asteroidea). Marine Biology, 69(2):175-185.

Black, K. P., and P. J. Moran. 1991. Influence of hydrodynamics on the passive dispersal and initial recruitment of larvae of Acanthaster planci (Echinodermata: Asteroidea) on the Great Barrier Reef. Marine Ecological Progress Series, 69:55-65.

Bode, L., I. J. Dight, M. K. James, L. B. Mason, and J. P. Scandol. 1992. Modeling approach to hydrodynamics and the large-scale larval dispersal of Acanthaster planci. Great Barrier Reef Marine Park Authority Publisher.

Bruckner, A. W., R. J. Bruckner, and P. Sollins. 2000. Parrotfish predation on live coral: 'spot biting' and 'focused biting.' Coral Reefs, 19(1):50

Burke, L., K. Reytar, M. Spalding, A. Perry. 2011. Reefs at Risk Revisited. Washington, DC: World Resources Institute.

Chandramohan, P., N. M. Anand and B. U. Nayak. 1993. Shoreline dynamics of the Lakshadweep islands. Indian Journal of Marine Sciences, 22:198-202.

Chesher, R. H. 1969. Destruction of Pacific corals by the sea star Acanthaster planci. Science, 165:280281.

Endean, R. 1969. Report on investigations made into aspects of current Acanthaster planci (Crown of Thorn) infestations of the Great Barrier Reef. Brisbane: Fish Branch, Queensland Dept. of Primary Industries.

Endean, R., A. M. Cameron, and L. Devantier. 1988. Acanthaster planci predation on massive corals: the myth of rapid recovery of devastated reefs. In Proceedings of the 6th International Coral Reef Symposium, ed. J. H. Choat et al., pp. 143-148. Penang, Malaysia: ReefBase.

Glynn, P. W. 2004. High complexity food webs in low-diversity eastern Pacific coral-reef communities. Ecosystems, 7: 358-367.

Hoegh-Guldberg, O., P. J. Mumby, A. J. Hooten, R. S. Steneck, P. Greenfield, E. Gomez, C. D. Harvell, P. F. Sale, A. J. Edwards, K. Caldeira, N. Knowlton, C. M. Eakin, R. Iglesias-Prieto, N. Muthiga, R. H. Bradbury, A. Dubi, and M. E. Hatziolos. 2007. Coral reefs under rapid climate change and ocean acidification. Science, 318:1737-1742.

Hughes, T. P., A. H. Baird, D. R. Bellwood, M. Card, S. R. Connolly, C. Folke, R. Grosberg, O. HoeghGuldberg, J. B. C. Jackson, J. Kleypas, J. M. Lough, P. Marshall, M. Nyström, S. R. Palumbi, J. M. Pandolfi, B. Rosen, and J. Roughgarden. 2003. Climate change, human impacts, and the resilience of coral reefs. Science, 301:929-933.

Kumar, S. P., and T. G. Prasad. 1996. Winter cooling in the northern Arabian sea. Current Science, 71(11):834-841.

Kumar, S. P., R. P. Roshin, J. Narvekar, P. K. Dinesh Kumar, and E. Vivekanandan. 2009. Response of Arabian Sea to global warming and associated regional climate shift. Marine Environmental Research, 68(5):217-222. 
Loya, Y. 1978. Plotless and transect methods. In Coral Reefs: Research Methods, ed. D. R. Stoddart and R. E. Johannes, pp. 197-218. Monographs on Oceanic Methodology, No. 5. Paris: UNESCO Press.

Mapstone, B. D., and A. M. Ayling. 1998. An investigation of optimum methods and unit sizes for the visual estimation of abundances of some coral reef organisms. Great Barrier Reef Marine Park Authority Publisher, Research Publication 47.

McClanahan, T. R., S. D. Donner, J. A. Maynard, M. A. MacNeil, N. A. J. Graham, J. Maina, A. C. Baker, J. B. Alemu, M. Beger, S. J. Campbell, E. S. Darling, C. M. Eakin, S. F. Heron, S. D. Jupiter, C. J. Lundquist, E. McLeod, P. J. Mumby, M. J. Paddack, E. R. Selig, and R. Van Woesik. 2012. Prioritizing key resilience indicators to support coral reef management in a changing climate. PLoS ONE 7, e42884. http://dx.doi.org/10.1371/journal.pone.0042884.

Moran, P. J. 1990. Acanthaster planci (L.): biographical data. Coral Reefs, 9:95-96.

- 1996. The Acanthaster phenomenon. Oceanography Marine Biology:An Annual Review, 24:379-480.

Moron, P. J., and G. De'ath. 1992. Estimates of the abundance of the crown-of-thorns starfish Acanthaster planci in out breaking and non-out breaking populations on reefs within the Great Barrier Reef. Marine Biology, 113:509-515.

Pillai, C. S. G. 1986. Status of coral reefs in Lakshadweep. Marine Fisheries Information Service Technical and Extension Series, 68:38-41.

Porter, J. W. 1972. Predation by Acanthaster and its effect on coral species diversity. The American Naturalist, 106:487-492.

Pratchett, M. S. 2001. Influence of coral symbionts on feeding preferences of crown-of-thorns starfish Acanthaster planci in the western Pacific. Marine Ecological Progress Series, 214:111-119.

Ravindran, J., R. Chandralatha, and S. Raghukumar. 1988. Disease and stress-induced mortality of corals in Indian reefs and observations on bleaching of corals in the Andamans. Current Science, 76:233-241.

Rotjan, R. D., and S. M. Lewis. 2008. Impact of coral predators on tropical reefs. Marine Ecological Progress Series, 367:73-91.

Rotjan, R. D., J. L. Dimond, D. J. Thornhill, J. J. Leichter, B. S. T. Helmuth, D. W. Kemp, and S. M. Lewis. 2006. Chronic parrotfish grazing impedes coral recovery after bleaching. Coral Reefs, 25:361-368.

Selig, E. R., C. D. Harvell, J. F. Bruno, B. L. Willis, C. A. Page, K. S. Casey, and H. Sweatman. 2006. Analyzing the relationship between ocean temperature anomalies and coral disease outbreaks at broad spatial scales. In Coral Reefs and Climate Change: Science and Management, ed. J. Phinney, O. Hoegh-Guldberg, J. Kleypas, W. Skirving, and A. Strong, pp 61:111-128. AGU Coastal and Estuarine Series. Washington, DC: American Geophysical Union.

Stella, J. S., M. S. Pratchett, P. A. Hutchings, and G. P. Jones. 2011. Coral-associated invertebrates: diversity, ecology importance and vulnerability to disturbance. Oceanography Marine Biology Annual Review, 49:43-104.

Sweatman, H., S. Delean, and C. Syms. 2011. Assessing loss of coral cover on Australia's Great Barrier Reef over two decades, with implications for longer-term trends. Coral Reefs, 30:521-531.

Van Woesik, R. 1994. Contemporary disturbances to coral communities of the Great Barrier Reef. Journal of Coastal Research, 12:233-252. 